\title{
Relação entre o uso de telas e o envelhecimento da pele: atualização clínica
}

\author{
Relationship between the use of screens and skin aging: clinical update
}

Relación entre el uso de pantallas de dispositivos electrónicos y elenvejecimiento cutáneo: actualización clínica

Antônio Viana Neves Neto ${ }^{1 *}$, Kttya Nardy Drumond ${ }^{1}$, Aline Lubiana ${ }^{1}$, Ana Luiza Souza da Silveira², Fabrícia Araújo e Silva ${ }^{1}$, Gustavo Neves Moreira ${ }^{1}$, Marco Aurélio Moreira Júnior ${ }^{3}$, Patrícia Peres de Barros $^{1}$, Márcia Farsura de Oliveira ${ }^{1}$.

\section{RESUMO}

Objetivo: Revisar em literatura a relação entre o uso de telas e o processo de envelhecimento da pele. Realizar uma atualização clínica sobre o tema descrevendo as principais descobertas até o momento. Revisão bibliográfica: O uso de aparelhos como smartphones, tablets, televisores, entre outros dispositivos, irradia a luz visível em um comprimento de onda capaz de alterar o funcionamento do DNA da pele e desencadear a liberação de espécies reativas de oxigênio em fibroblastos. Em um curto período de tempo esse hábito acelera o processo de envelhecimento cutâneo. Ainda não existem estudos robustos que tenham avaliado o efeito da exposição à luz visível por um longo intervalo. Considerações finais: $O$ uso de dispositivos de telas, que emitem luz visível, acelera o processo de envelhecimento cutâneo, através do aumento do estresse oxidativo e causam danos a pele. Sugere-se a realização de mais pesquisas sobre 0 tema que abordem também as consequências dessa exposição ao longo dos anos.

Palavras-chave: Envelhecimento cutâneo, Luz visível, Uso de telas.

\begin{abstract}
Objective: To review in literature the relationship between the use of screens and the skin aging process. Carry out a clinical update on the topic describing the main findings so far. Bibliographic review: The use of devices such as smartphones, tablets, televisions, among other devices, radiates visible light in a wavelength capable of altering the functioning of the DNA of the skin and trigger the release of reactive oxygen species in fibroblasts. In a short period of time this habit accelerates the skin aging process. There are still no robust studies that have evaluated the effect of exposure to visible light for a long period of time. Final considerations: The use of screen devices, which emit visible light, accelerate the skin aging process, by increasing oxidative stress and causing damage to the skin. It is suggested to carry out more research on the topic that also addresses the consequences of this exposure over the years.
\end{abstract}

Keywords: Skin aging, Visible light, Use of screens.

\section{RESUMEN}

Objetivo: Revisar en la literatura la relación entre el uso de pantallas y el proceso de envejecimiento cutáneo. Realizar una actualización clínica sobre el tema describiendo los principales hallazgos hasta el momento.

\footnotetext{
${ }^{1}$ Faculdade Dinâmica do Vale do Piranga (FADIP), Ponte Nova - MG. *E-mail: netoviana@live.com

2 Universidade Iguaçu (UNIG), Itaperuna - RJ.

${ }^{3}$ Faculdade de Medicina de Barbacena (FAME/FUNJOB), Barbacena - MG.
} 
Revisión bibliográfica: El uso de dispositivos como smartphones, tablets, televisores, entre otros dispositivos, irradia luz visible en una longitud de onda capaz de alterar el funcionamiento del ADN del piel y desencadenar la liberación de especies reactivas de oxígeno en los fibroblastos. En poco tiempo, este hábito acelera el proceso de envejecimiento de la piel. Todavía no existen estudios sólidos que hayan evaluado el efecto de la exposición a la luz visible durante un largo período de tiempo. Consideraciones finales: El uso de dispositivos de pantalla, que emiten luz visible, aceleran el proceso de envejecimiento de la piel, al aumentar el estrés oxidativo y causar daños en la piel. Se sugiere realizar más investigaciones sobre el tema que también aborden las consecuencias de esta exposición a lo largo de los años.

Palabras clave: Envejecimiento cutáneo, Luz visible, Uso de pantallas.

\section{INTRODUÇÃO}

A pele é, anatomicamente, constituída por três camadas: epiderme, derme e camada subcutânea e tem como uma de duas principais funções no organismo o revestimento e a proteção contra agressores externos, sendo uma ferramenta importante do sistema imune. É considerada o maior órgão do corpo humano e tem uma íntima relação com o funcionamento do organismo, sendo um importante marcados do envelhecimento do corpo (GUERRA RF, et al., 1990).

A segunda camada da pele, a derme, é constituída por fibras de colágeno e elastina. Sua principal função é a sustentação, mas ela participa também, dos processos fisiopatológicos do órgão. O colágeno, constituinte da derme, é sintetizado pelos fibroblastos, que são células constituintes do tecido conjuntivo e que auxiliam na formação de substâncias fundamentais amorfas. Nos adultos, os fibroblastos estão presentes em menor quantidade, quando comparados às crianças e os adolescentes e com o envelhecimento essa diferença tende a ser cada vez maior (BERNARDO AF, et al., 2019).

Com o passar dos anos, assim como outros órgãos, a pele se deixa afetar por um processo inato de envelhecimento. Neste caso, a sequência contínua de fatos ou operações que apresentam certa unidade ou que se reproduzem com certa regularidade diminuição orgânica e funcional, não decorrente de doença, sofre influência tanto de fatores endógenos, quanto exógenos. Em relação às alterações intrínsecas, pode-se citar a perda de algumas de suas funções, como aquelas relacionadas à barreira com diminuição da capacidade de reposição de lipídeos do estrato córneo, redução dos corpúsculos de Meissner e Pacini, degeneração da capacidade elástica dos vasos sanguíneos e alterações no fluxo no sistema circulatório cutâneo com vasoatividade reduzida, perda da capacidade de oxidação, entre outros (PADILHA-GONÇALVES A, 1991; ORTOLAN MCA, et al., 2013 e ORIÁ RB, et al. 2003.)

As glândulas sebáceas e sudoríparas são responsáveis pela manutenção da camada lipídica da pele. Essa camada funciona como uma barreira protetora, atuando na imunidade e na hidratação da pele (ADDOR FAZ e AOKI V, 2010). Os corpúsculos de Meissner, por sua vez, são receptores sensoriais que captam sensações de toque. Já os corpúsculos de Pacini são os responsáveis pela sensação de pressão. Com o tempo e a perda desses corpúsculos, existe a diminuição da sensibilidade cutânea (CECCATO M, et al., 2011).

Conforme o processo de envelhecimento acontece, a redução do número de fibroblastos, da multiplicação celular e o comprometimento da síntese de proteínas (como o colágeno e a elastina, por exemplo), influenciam na densidade, resistência, elasticidade e sustentação da pele culminando em apresentações como atrofia, aparecimento de rugas, ptose e diminuição da força cutânea (BERNARDO AF, et al., 2019).

Os vasos sanguíneos, que entre outras substâncias, possui em sua constituição o colágeno, com o passar do tempo, perdem sua elasticidade e sua capacidade de organização dessas fibras, especialmente após a sexta década de vida. Além disso, com o envelhecimento a vascularização da derme torna-se mais irregular e dilatada e uma consequente redução do número de vasos sanguíneos funcionantes contribuem para o aparecimento de rugas e outras apresentações clínicas (MORGANA C, et al., 2013).

As alterações intrínsecas do envelhecimento atingem todas as camadas da pele. A epiderme torna-se mais fina, devido à diminuição da camada córnea, com redução do número de melanócitos, e lipídeos. Vale 
ressaltar, que os melanócitos, apesar de diminuírem sua atividade, tornam-se mais reativos desencadeando o aparecimento de manchas. Na derme, as alterações são as grandes responsáveis pelo aparecimento de flacidez e rugas, sendo elas: depressão da das papilas dérmicas, comprometimento do fluxo sanguíneo cutâneo pelas alterações citadas anteriormente, redução do número de fibroblastos/colágeno/elastina e diminuição de ácido hialurônico com perda da hidratação cutânea (BERNARDO AF, et al., 2019).

Os fatores exógenos, por sua vez, podem ser desencadeados pelo tabagismo que, além da redução do fluxo sanguíneo, provoca a perda da elasticidade cutânea pelo calor da chama e o contato com a fumaça e outros hábitos como alimentação não balanceada, na qual o aumento dos níveis de glicose levam a um fenômeno chamado de glicação que fazem com que as proteínas percam sua função, tornando-as prejudiciais assim como acontece com os radicais livres; o consumo excessivo de álcool que acaba degradando o colágeno e contribuindo para o aparecimento prematuro de linhas e rugas de expressão; a realização movimentos musculares repetitivos que formam linhas mais profundas gerando as rugas, e a exposição à radiação solar que é o maior exemplo, causando atrofia das áreas expostas ao sol e danos ao ácido desoxirribonucleico (DNA), (SUEHARA LY, et al., 2006),

O fotoenvelhecimento é um processo cumulativo, que resulta em afinamento da camada dermoepidérmica (atrofia), mutações no DNA incluindo resistência celular a apoptose (mecanismo programado de morte celular das células cutâneas e o aceleramento do processo de envelhecimento. Partindo da premissa que de a luz solar possui uma irradiação capaz de causar os referidos danos a pele, a exposição a outros tipos de comprimento de onda poderia também desencadear, a longo prazo, alterações maléficas. Nesse sentido, temse discutido o aparecimento de outros agressores externos que podem acelerar esse processo, sendo a luz visível, presente em aparelhos eletrônicos, um deles (MONTAGNER C, 2009).

A Luz Gerada por Dispositivos Eletrônicos (LGDP) inclui a luz visível, a radiação ultravioleta (UV)e os raios infravermelhos. Estudos recentes, que serão discutidos nesse artigo, têm investigado o efeito que a exposição a telas pode exercer sobre o envelhecimento cutâneo e o mecanismo envolvido por trás disso. Após diversas análises descobriu-se que, em curto prazo, a exposição a esses dispositivos é capaz de aumentar as espécies reativas de oxigênio nos fibroblastos humanos, podendo desempenhar um importante no processo de envelhecimento cutâneo (AUSTIN E, et al., 2018; ARJMANDI N, et al., 2018; ZASTROW L, et al., 2009 e MAHMOUD BH, et al., 2008).

O estresse oxidativo, causado por espécies reativas de oxigênio, leva a uma perioxidação dos ácidos graxos que constituem a dupla camada lipídica da membrana celular. A instabilidade energética causada a partir dessa oxidação, gera uma série de modificações estruturais culminando como resultado em morte celular. Em 1956, uma teoria criada por Denham Harman associou o estresse oxidativo e a produção de radicais livres ao envelhecimento, devido a atuação desses radicais no organismo, resultando em alterações no DNA, desidrogenação, hidroxilação e por agirem na glicação que, como citada anteriormente, atua como responsável pela perda das funções biológicas das proteínas, incluindo as funções exercidas pelo colágeno. Desde então, a busca por meios de prevenir a exposição a processos geradores de estresse oxidativo tem sido constante, com o objetivo de driblar o envelhecimento (HIRATA LL, et al., 2004).

Se por um lado a descoberta de tais fontes luminosas como fontes produtoras de radicais livres é um avanço no mundo da estética, por outro abre precedente para um grande impasse da era moderna. Cada vez mais, os smartphones fazem parte do cotidiano das pessoas, seja seu uso para momentos de lazer ou como meio de trabalho, as pessoas passam muitas horas dos seus dias frente a um desses aparelhos, principalmente com o advento das profissões digitais como influenciadores, por exemplo. Além do mais, registram-se momentos com uma frequência nunca vista antes, e uma grande parcela da população, que trabalha com o mundo digital, quase que diariamente, está exposta aos flashes e a exposição ao brilho dos seus telefones. $O$ uso de telas tem sido cada vez maior seja pelo público infanto juvenil ou pelos adultos, a tecnologia tem ganhado cada vez mais espaço nas empresas e das residências da população em geral (COUTINHO GL, 2014).

No entanto, a cada dia os avanços sobre o processo de envelhecimento, no sentido de novas pesquisas e conhecimento sobre o processo também tem ganhado destaque. Com o envelhecimento da população se 
torna maior a busca em retardar este processo. No mundo da ciência e da tecnologia o rejuvenescimento facial ou, pelo menos, o retardamento do envelhecimento cutâneo tem atraído a atenção de pesquisadores e indústrias do ramo (ARJMANDI N, et al., 2018).

O presente artigo, buscou revisar a literatura médica com o objetivo entender a relação entre o uso de telas relacionadas a aparelhos eletrônicos e o envelhecimento da pele, destacando os principais mecanismos fisiopatológicos envolvidos neste processo e os métodos de prevenção direcionados ao fotoenvelhecimento, seja ele por luz solar ou luz artificial, bem como realizar uma atualização clínica sobre o tema.

\section{REVISÃO BIBLIOGRÁFICA}

\section{Relação entre o aumento da expectativa de vida e envelhecimento cutâneo}

Com o aumento da expectativa e melhoria da qualidade de vida no país, a população tende a viver por mais tempo e envelhecer com mais saúde (CAMARGOS MCS, et al., 2019). Essa mudança demográfica faz com que as pessoas passem a se preocupar mais com o processo de envelhecimento e com cuidados a longo prazo, tendo em vista que o número de pessoas vivenciando o processo de envelhecimento irá aumentar nos próximos anos. As mudanças de atitudes encorajadas por essa nova demografia refletem não só em hábitos de vida mais saudáveis, mas também no aumento das buscas por cuidados estéticos, visando retardar o processo de envelhecimento da pele (TEIXEIRA MCT, et al., 2007).

Os hábitos sociais mudaram muito ao longo dos anos e o processo de envelhecimento da pele, que antes tinha como principal vilã a luz solar, passou a sofrer influência de novos fatores externos, como o a irradiação por luz visível, por exemplo. A introdução de dispositivos de alta tecnologia tem sido cada vez mais significativa e tem atingido adultos e idosos. Segundo o Instituto Brasileiro de Geografia e Estatística (IBGE), em 2018, 79\% das pessoas possuíam pelo menos um dispositivo eletrônico de tela em sua residência e estudos demonstraram que $79,5 \%$ dos jovens usam de forma excessiva esses dispositivos eletrônicos, hábito esse que até algum tempo não era comum (COUTINHO GL, 2014).

A inserção de dispositivos que emitem luz visível no cotidiano da população, além dos televisores e iluminação artificial é recente, contudo, estudos clínicos já demonstraram a capacidade de alteração do DNA que esse tipo de irradiação é capaz de provocar, além do aumento da produção de espécies reativas de oxigênio e sua influência nos processos de apoptose e necrose no funcionamento da renovação celular da pele (MAHMOUD BH, et al., 2008; ARJMANDI N, et al., 2018; AUSTIN E, et al., 2018 e ZASTROW L, et al., 2009).

A produção de estresse oxidativo no organismo humano pode acontecer de duas formas: através de processos intrínsecos ou extrínsecos. Endogenamente, acontece a partir de oxidações mitocondriais, fagocitoses que são iniciadas em meio a uma reação inflamatória e através da ativação do metabolismo do ácido araquidônico. Já em relação aos fatores externos, a exposição à luz, seja ela de origem solar ou por meio de dispositivos, é capaz de aumentar esse processo, que tem como resultado o aceleramento do envelhecimento cutâneo. Os fatores endógenos são mais difíceis de serem interrompidos, tendo em vista que as alterações fisiológicas sofridas pelo organismo com o passar dos anos são implacáveis. No entanto, os fatores extrínsecos são preveníveis e podem ser evitados adotando-se determinados hábitos e condutas, como hábitos de vida e alimentação saudáveis, uso de ferramentas para fotoproteção, entre outros (HIRATA LL, et al., 2004).

\section{Influência dos dispositivos de tela no envelhecimento da pele}

Os primeiros estudos relacionados à exposição a luz e os efeitos que isso poderia gerar no corpo humano são de 1671, feitos por Newton. A forma como radiação ultravioleta é prejudicial, já é bem estabelecida em literatura. No entanto, os efeitos da luz visível e da radiação infravermelha, até pouco tempo atrás, não eram alvo de estudos e, até o presente momento, não são totalmente elucidados. Ainda assim, já se sabe que algumas reações como vermelhidão, pigmentação, dano térmico e produção de radicais livres são fenômenos relacionados a esse tipo de exposição (MAHMOUD BH, et al., 2008). 
Com o avanço da tecnologia na era moderna, o ser humano está em constante exposição à luz, mesmo nos períodos noturnos, ainda que sejam de fontes artificiais. $O$ envelhecimento da pele, além dos fatores intrínsecos desencadeados pela idade - já citados anteriormente - está intimamente relacionado ao estresse oxidativo sofrido externamente. Descobertas recentes relacionara, o aumento do estresse oxidativo ao uso de dispositivos de tela e concluíram que uma hora apenas de exposição a esse tipo de luz visível já é, comprovadamente, capaz de aumentar o processo de oxidação na pele (ARJMANDI N, et al., 2018).

Esse entendimento foi possível graças as pesquisas que relacionaram o efeito da luz visível em fibroblastos humanos. Depois de uma hora de exposição a uma irradiância semelhante à de eletrônicos utilizados no cotidiano como iPhone 8+, iPhone 6 e iPad, por exemplo, houve um aumento das espécies reativas de oxigênio em mais de $80 \%$. Com todos os dispositivos, chegando a um índice de $92,98 \%$ de aumento após a irradiância semelhante a de um iPad de primeira geração, durante uma hora de exposição. Entende-se que este tipo de alteração é reproduzível para outros dispositivos em formato Android, tablets, telas de computadores e televisores. Ainda neste mesmo estudo foram avaliadas alterações como necrose cutânea e o desencadeamento de processos de morte celular. Em relação às apoptoses não houve mudança significativa após o tempo de uso estudado (AUSTIN E, et al., 2018).

Em outras palavras, a luz visível azul, de comprimento de onda entre 400 e $500 \mathrm{~nm}$, que pode ser encontrada de forma artificial através dos dispositivos eletrônicos usados no dia a dia, após uma exposição prolongada e repetida (mais de uma hora) aumenta a quantidade de danos ao DNA e consequentemente a morte de células e tecidos, causando danos a barreira cutânea. Esse fenômeno capaz de mutar o DNA e de provocar um aumento do estresse oxidativo nas células da pele culmina em cascatas responsáveis pela perda da capacidade elástica, regenerativa e de barreira da pele, levando consequentemente a um envelhecimento precoce (COATS JG, et al., 2020).

Além disso, outros ensaios realizados elucidaram que o espectro de luz visível usados nos flashes de selfies também podem causar danos a pele, acelerando o seu envelhecimento (ARJMANDI N, et al., 2018). O ser humano nunca produziu tantos autorretratos como nos dias de hoje e a exposição a esse tipo de hábito tem se iniciado cada vez mais cedo, em uma frequência muito superior à de algumas décadas. Uma vez determinado o fato de que a geração de espécies reativas de oxigênio é proporcional a intensidade da luz visível, o fotoenvelhecimento gerado por dispositivos eletrônicos será cada vez mais significativo (ZASTROW L, et al., 2009).

A luz visível pode ser dividida entre aquelas que são produzidas pelas lâmpadas de Light Emitting Diode (LED) que iluminam o interior de dispositivos eletrônicos como televisores, computadores, tablets, e as que usam tecnologia Diodo Orgânico Emissor de Luz (OLED) ou Tecnologia Active-Matrix Organic Light Emitting Diode (AMOLED). O comprimento de onda da luz azul que é potencialmente prejudicial aos olhos e a pele humana gira em torno de 415 a $455 \mathrm{~nm}$. Sabe-se que existem opções de filtros que tem como o objetivo diminuir a irradiância da luz azul. Os aparelhos eletrônicos mais modernos possuem ainda a opção de funcionamento em modo noturno, onde a luz azul é trocada por uma luz com intensidade menor, na tentativa de trazer conforto aos olhos em períodos noturnos. Após um estudo realizado em por Renard $\mathrm{G}$ e Jeid $\mathrm{J}$ (2016), observou-se que embora existam esses filtros que protejam contra a luz LED, o único meio de se proteger da emissão causada pelas luzes OLED e AMOLED seria a redução do tempo de uso.

\section{Formas de prevenção ao fotoenvelhecimento}

Para a radiação solar, existem formas de prevenção eficazes como o uso de roupas com fator de proteção, fotoprotetores em creme que combatem não só o fotoenvelhecimento como também o desenvolvimento de neoplasias cutâneas (SCHALKA S e REIS VM, 2011; BALOGH TS, et al., 2011). Além disso, dieta rica em vitaminas antioxidantes, uso de dermocosméticos tópicos com formas associadas a vitamina $C, A$ e E, e ativos como Argireline são ferramentas utilizadas para o tratamento do envelhecimento cutâneo (TESTON AP, et al., 2010).

O desenvolvimento de filtros solares com pigmento, com a proposta de proteção para luz, apesar de serem uma ferramenta importante para auxiliar na prevenção do envelhecimento causado pela luz visível ainda não 
demonstraram benefícios suficientemente, a ponto de serem $100 \%$ eficazes para a proteção contra esses danos (SCHALKA S, et al., 2012). Em relação às luzes de LED, o uso de filtros exerce alguma proteção em relação a sua exposição, no entanto para as tecnologias OLED e AMOLED, como demonstrado em estudo, e citado anteriormente neste artigo, a melhor forma de prevenção é a redução do tempo de uso (RENARD G e JEID J, 2016).

Existem poucos artigos disponíveis em literatura abordando o uso de telas relacionados ao envelhecimento da pele, uma vez que os estudos publicados são muito recentes. Ainda não foram realizados/publicados estudos sobre esse assunto em literatura nacional. Além disso, as pesquisas, até o momento, estão relacionadas com os danos a curto prazo, as consequências a longo prazo necessitam de mais estudos e de um tempo maior de pesquisas e ensaios clínicos, pois, como dito anteriormente, a tendência é que a população de adultos jovens de hoje em dia, envelheçam sob os efeitos das luzes visíveis emitidas por dispositivos eletrônicos de uma forma significativa e muito distinta da que é conhecida até o momento, uma vez que a luz visível azul provavelmente exerça um papel significativo no fotoenvelhecimento. Sugere-se que novos estudos sejam realizados nesta área, sobretudo em países tropicais como o Brasil, onde a população está sob os efeitos da luz solar a maior parte do ano e em exposição, cada vez maior, a luz visível (ZASTROW L, et al., 2009).

\section{CONSIDERAÇÕES FINAIS}

O uso de telas, através de smartphones, televisores, tablets, etc, tem aumentado cada vez mais e a exposição a luz visível emitida por esses dispositivos é capaz de gerar, comprovadamente, modificações no funcionamento do tecido cutâneo, criando um ambiente favorável a alterações do DNA e aumentando a produção de espécies reativas de oxigênio. Estudos realizados, até o momento, comprovaram que uma hora de exposição a esses dispositivos é o suficiente para o desencadeamento desse processo que culmina na aceleração do envelhecimento da pele. As consequências da exposição a longo prazo ainda não são conhecidas. Sugere-se mais estudos nesta área sobre os efeitos após exposições prolongadas bem como sobre novos métodos capazes de prevenir o envelhecimento cutâneo relacionado ao uso de telas, para assim, ampliar as informações sobre o assunto na comunidade científica.

\section{REFERÊNCIAS}

1. ADDOR FAZ, AOKI V. Barreira cutânea na dermatite atópica. An. Bras. Dermatol, 2010. 85(2): 184-194.

2. ARJMANDI N, et al. "Can Light Emitted from Smartphone Screens and Taking Selfies Cause Premature Aging and Wrinkles?." Journal of biomedical physics \& engineering, 2018. 8(4): 447-452.

3. AUSTIN E, et al. "Electronic device generated light increases reactive oxygen species in human fibroblasts." Lasers in surgery and medicine, 2018.

4. BALOGH T.S, et al. Proteção à radiação ultravioleta: recursos disponíveis na atualidade em fotoproteção. An Bras Dermatol. 2011. 86(4): 732-42.

5. BERNARDO AF, et al. Pele: Alterações Anatômicas e Fisiológicas do Nascimento à Maturidade. Revista Saúde em Foco. Ed 11르, 2019.

6. CAMARGOS MCS, et al. Estimativas de expectativa de vida livre de incapacidade funcional para Brasil e Grandes Regiões, 1998 e 2013. Ciência \& Saúde Coletiva [online] 2019. 24 (3).

7. CECCATO M, et al. Efeito de uma sessão de exercício resistido na sensibilidade cutânea em idosas hipertensas e normotensas fisicamente ativas. Rev. bras. cineantropom. desempenho hum. (Online), 2011. 13(6): 409-414.

8. COATS J G, et al. "Blue Light Protection, Part I-Effects of blue light on the skin." Journal of cosmetic dermatology, 2020. 20(3): 714-717.

9. COUTINHO GL. A Era dos Smartphones: Um estudo exploratório sobre o uso dos Smartphones no Brasil. Brasília, DF, 2014.

10. GUERRA RF, et al. Envelhecimento Cutâneo. Fisiopatologia e Perspectiva Clínica. Acta Médica Portuguesa.,1990. 3: 311-318.

11. HIRATA LL, et al. Radicais Livres e o Envelhecimento Cutâneo. Acta Farm. Bonaerense 2004. 23(3): 418-24.

12. LUCENA, J.M.S et al. Prevalência de tempo excessivo de tela e fatores associados em adolescentes. Revista Paulista de Pediatria, 2015. 33(4): 407-414.

13. MAHMOUD BH, et al. "Effects of visible light on the skin." Photochemistry and photobiology, 2008. 84(2): 450-62.

14. MONTAGNER Suelen; COSTA Adilson. Bases biomoleculares do fotoenvelhecimento. An. Bras. Dermatol, 2009. 84(3): 263-269. 
15. MORGANA C, et al. Influência do envelhecimento na qualidade da pele de mulheres brancas: o papel do colágeno, da densidade de material elástico e da vascularização. Rev Bras Cir Plást. 2013. 8(1): 41-48.

16. ORIÁ RB, et al. Estudo das alterações relacionadas com a idade na pele humana, utilizando métodos de histomorfometria e autofluorescência. An bras Dermatol, 2003. 78(4): 425-434.

17. ORTOLAN MCA. et al. Influência do envelhecimento na qualidade da pele de mulheres brancas: o papel do colágeno, da densidade de material elástico e da vascularização. Rev. Bras. Cir. Plást., 2013. 28(1): 41-48.

18. PADILHA-GONÇALVES, A. Envelhecimento cutâneo cronológico. AnBrasDermatol. 1991. 66(1): 4-6.

19. RENARD G e JEID J. "Lesdangers de lalumièrebleue: lavérité!" [The dangers of blue light: True story!]. Journal francaisd'ophtalmologie. 2016; 39(1): 5483-8.

20. SCHALKA S, et al. Proteção oferecida por fotoprotetores contra luz visível - uma proposta de avaliação. Surgical \& Cosmetic Dermatology, 2012; 4(1): 45-52.

21. SCHALKA S, REIS VM. Fator de proteção solar: significado e controvérsias. An. Bras. Dermatol, 2011; 86(3): 507515.

22. SUEHARA LY, et al. Avaliação do envelhecimento facial relacionado ao tabagismo. An. Bras. Dermatol, 2006; 81(1): 34-39.

23. TEIXEIRA MCT, et al. Envelhecimento e rejuvenescimento: um estudo de representação social. Rev. bras. geriatr. gerontol., 2007; 10(1): 49-72.

24. TESTON AP, et al. Envelhecimento Cutâneo: Teoria Dos Radicais Livres E Tratamentos Visando A Prevenção e o Rejuvenescimento. Revista Uningá, [S.I.], 2010; 24(1) 354p.

25. ZASTROW L, et al. "UV, sichtbaresLicht, Infrarot. Welche Wellenlängen produzieren oxidativen Stress in menschlicher Haut?" [UV, visible and infrared light. Which wavelengths produce oxidative stress in human skin?]. Der Hautarzt; Zeitschrift fur Dermatologie, Venerologie, und verwandteGebiete, 2009; 60(4): 310-7. 